\title{
A comparison of conventional and segmental rotor 12/10 switched reluctance motors
}

\author{
Xu Deng \\ School of Engineering \\ Newcastle University \\ Newcastle Upon Tyne, United Kingdom \\ xu.deng@ncl.ac.uk
}

\author{
Barrie Mecrow \\ School of Engineering \\ Newcastle University \\ Newcastle Upon Tyne, United Kingdom \\ barrie.mecrow@ncl.ac.uk
}

\begin{abstract}
Segmental rotor Switched Reluctance Machines (SRMs) have been demonstrated to produce more torque than toothed rotor SRMs because each coil is able to link more magnetic flux. This paper considers a six-phase segmental rotor SRM and compares it to a conventional SRM with the same lamination length and outer dimensions. Both fully-pitched (FP) and single-tooth wound (STW) motor configurations of the segmental rotor SRM are investigated. The FP winding machine produces higher torque than the single tooth winding machine when using the same phase conduction angles but has unacceptably long end windings. Optimized conduction widths and current shapes are subsequently applied to the single tooth winding segmental rotor SRM. The segmental SRM is shown to produce about $10 \%$ higher rated torque, with less core loss and copper loss than the conventional SRM throughout the whole speed range.
\end{abstract}

Keywords-switched reluctance motor, segmental rotor, multiphase machine, losses, efficiency

\section{INTRODUCTION}

Switched Reluctance Machines (SRMs) are experiencing a resurgence in interest because of the desire to avoid using rare earth magnets. They offer the potential for relatively high torque densities $[1,2]$, along with a simple, low loss rotor construction. However, their torque density remains poorer than that of rare earth permanent-magnet motors, and they have a reputation for high torque ripple and acoustic noise.

The use of a segmental rotor configuration of SRM has been investigated to improve torque density [3, 4]. The segmental rotor structure gives an increase in the aligned inductance of the machine, whilst maintaining a low unaligned inductance. The results of this work summarized that an increase in torque capability of up to $40 \%$ was possible with segmental rotor machines when compared to a conventional SRM with same dimensions. Although the segmental rotor manufacturing process is a little complex compared with the rotor in the conventional SRM, the segmental rotor does not have any mechanical saliency, which can reduce the windage [5].

In the last decade there have been several publications on segmental rotor/stator designs for a range of applications. A axial field SRM with a segmental rotor has even been proposed [6]. The concept of the segmental rotor focuses the magnetic flux into short flux paths which can reduce the core loss of the rotor and give higher efficiency. A three-phase 12/8 SRM with a segmental rotor was proposed for a vehicle cooling fan application [7]. This structure had short flux paths and no flux reversals in the stator of the motor. Compared with toothed rotor SRMs, the segmental rotor structure helped increase the electric utilization and decrease the Magneto
Motive Force (MMF) requirement and core losses. A highspeed segmental stator SRM was proposed in [8] for an airblower application. The stator of the 4/3 SRM was constructed with two segmental C-cores. The flux followed in a short closed loop in each C-core. Once more, the absence of reversal flux in the stator helped the motor to reduce core loss and give higher efficiency.

A variety of winding arrangements have been studied. A 12/8 segmental SRM with a fully-pitched winding and a 12/10 segmental rotor SRM with a hybrid stator and single-tooth winding had similar torque performance[3]. However, the fully-pitched type had longer end windings, causing higher winding loss [9].

As power electronics costs fall, increasing the phase number is a simple and generally accepted way to reduce torque ripple. Over the last few years machines with higher phase numbers have been considered due to their potential for lower torque ripple, less phase current for a given power rating and better fault-tolerant ability compared with traditional machines [10]. A six-phase SRM and its drive system has been proposed and investigated, examining winding connection effects, converter topologies and control methods [11-13]. Since six-phase toothed SRMs have lower torque ripple, and segmental SRMs often have higher torque density, it is interesting to investigate the performance of a segmental rotor SRM with a higher phase number.

In this paper, a six-phase segmental rotor SRM is proposed and compared with the conventional toothed rotor SRM in terms of torque capability, losses and efficiency. Both fullypitched (FP) and single-tooth wound (STW) motor configurations of the segmental rotor SRM are investigated. Different current shapes and conduction widths are applied to the segmental rotor SRM to produce an optimized performance. Current control and voltage control of the segmental rotor machine are investigated to compare its performance with the conventional toothed rotor SRM throughout the speed range.

\section{SEGMENTAL Rotor SRM DESIGN}

\section{A. Conventional toothed rotor six-phase SRM}

Fig. 1 shows the rotor and stator of the conventional sixphase 12/10 SRM prototype, and Table I gives the design parameters for this machine. All the segmental rotor SRM designs proposed in this paper will be compared with it in terms of copper loss, core loss, efficiency and torque capability. 


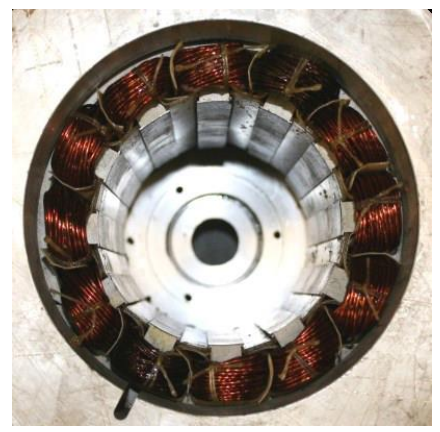

(a)

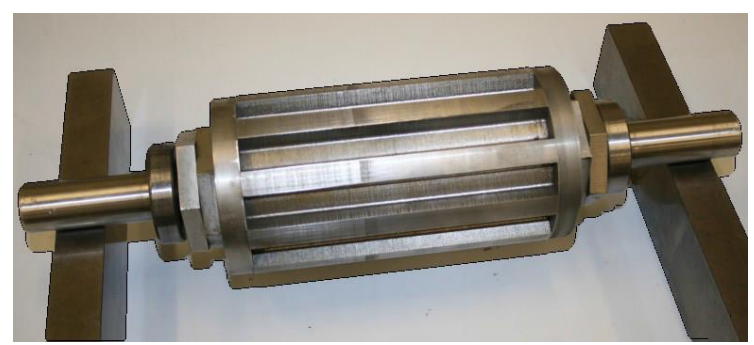

(b)

Fig. 1. Six-phase 12/10 SRM prototype: (a) wound stator (b) rotor.

TABLE I

DESIGN PARAMETERS OF THE CONVENTIONAL TOOTHED ROTOR SIX-PHASE SRM PROTOTYPE

\begin{tabular}{|c|c|}
\hline Number of Stator Teeth & 12 \\
\hline Number of Rotor Teeth & 10 \\
\hline Axial Length & $150.0 \mathrm{~mm}$ \\
\hline Stator Outer Diameter & $150.0 \mathrm{~mm}$ \\
\hline Stator Inner Diameter & $91.4 \mathrm{~mm}$ \\
\hline Stator Core-Back Depth & $11.0 \mathrm{~mm}$ \\
\hline Stator Tooth Width & $11.4 \mathrm{~mm}$ \\
\hline Airgap Length & $0.5 \mathrm{~mm}$ \\
\hline Rotor Outside Diameter & $90.8 \mathrm{~mm}$ \\
\hline Rotor Insider Diameter & $36.0 \mathrm{~mm}$ \\
\hline Rotor Core back Depth & $18.0 \mathrm{~mm}$ \\
\hline Rotor Tooth Width & $11.4 \mathrm{~mm}$ \\
\hline Turns per Phase & 100 \\
\hline Slot Fill Factor & 0.46 \\
\hline Winding Diameter & $1.4 \mathrm{~mm}$ \\
\hline Slot Area & $315 \mathrm{~mm}$ \\
\hline
\end{tabular}

\section{B. Segmental rotor six-phase SRM}

General topologies of a six phase toothed rotor SRM and a segmental rotor SRM are presented in Fig. 2. The segmental rotor SRM replaces the conventional, toothed rotor as shown in Fig. 2(a) with a rotor which is made up of a number of separate magnetically isolated segments as shown in Fig. 2 (b).

In order to obtain a basis for comparison, rotor and stator outside dimensions, stator core back, air gap, slot fill factor and lamination stack length of the segmental rotor SRM have been kept identical to those of the conventional toothed rotor SRM design. The design parameters of the segmental rotor SRM are shown in Table II. The segmental rotor SRM has longer tooth tip arcs to achieve a higher flux-linkage in the aligned position, which reduces the slot area from $315 \mathrm{~mm}^{2}$ to
$270 \mathrm{~mm}^{2}$. The conductor diameter of the two SRMs are $1.4 \mathrm{~mm}$, corresponding to 44 turns per coil in the segmental machine and 50 turns per coil in the toothed rotor machine.

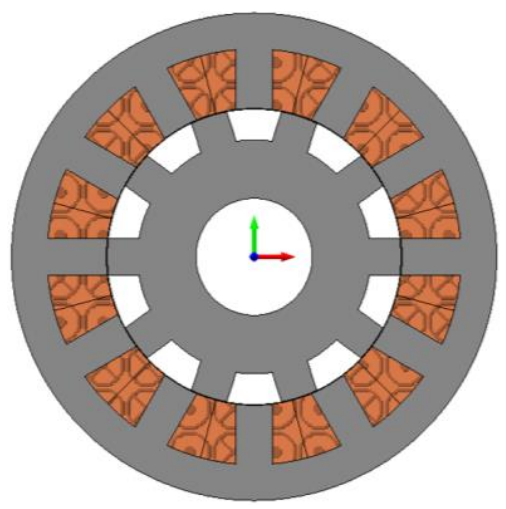

(a)

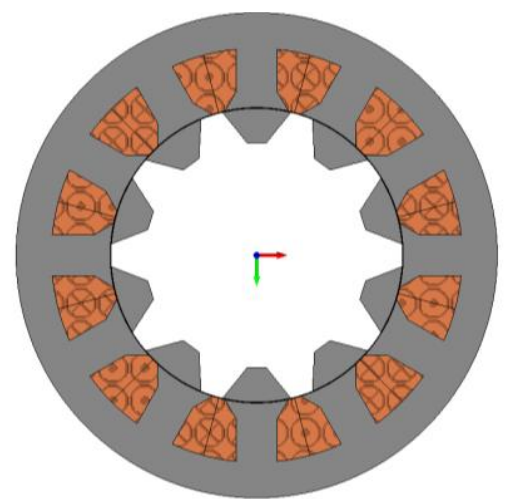

(b)

Fig. 2. General six-phase 12/10 SRM topologies: (a) conventional toothed rotor SRM (b) segmental rotor SRM.

TABLE II

DESIGN PARAMETERS OF THE SEgMENTAL ROTOR SIX-PHASE SRM PROTOTYPE

\begin{tabular}{|c|c|}
\hline & \\
\hline Number of Stator Teeth & 12 \\
\hline Number of Rotor Teeth & 10 \\
\hline Axial Length & $150.0 \mathrm{~mm}$ \\
\hline Stator Outer Diameter & $150.0 \mathrm{~mm}$ \\
\hline Stator Inner Diameter & $91.4 \mathrm{~mm}$ \\
\hline Stator Core-Back Depth & $11.0 \mathrm{~mm}$ \\
\hline Stator Tooth Width & $12.68 \mathrm{~mm}$ \\
\hline Airgap Length & $0.5 \mathrm{~mm}$ \\
\hline Rotor Outside Diameter & $90.8 \mathrm{~mm}$ \\
\hline Rotor Depth & $9.72 \mathrm{~mm}$ \\
\hline Rotor Tooth Width & $11.4 \mathrm{~mm}$ \\
\hline Stator Tooth Tip Arc Angle & $25^{\circ}$ \\
\hline Rotor Tooth Tip Arc Angle & $27^{\circ}$ \\
\hline Turns per Phase & 88 \\
\hline Stator Tooth Tip Taper Angle & $60^{\circ}$ \\
\hline Rotor Segment Taper Angle & $60^{\circ}$ \\
\hline Slot Fill Factor & 0.47 \\
\hline Winding Diameter & $1.4 \mathrm{~mm}$ \\
\hline Slot Area & $270 \mathrm{~mm}^{2}$ \\
\hline
\end{tabular}




\section{FINITE ELEMENT ANALYSIS}

\section{A. Single-phase excitation}

Finite Element Analysis (FEA) of the conventional toothed SRM winding configurations have been discussed in [11]. In the single-phase excitation simulation, there is a choice of polarities between the two coils of a phase. N-S polarities of a single-phase connection give rise to long flux paths via the full stator and rotor core whilst N-N polarities of excitation give rise to shorter flux paths which link adjacent teeth and create mutual coupling as shown in Fig. 3 (a) and (b). However, there are only short flux paths in the segmental rotor SRM (no matter N-S or N-N polarities) as there is no rotor core back providing long flux paths as shown in Fig. 3(c) and (d).

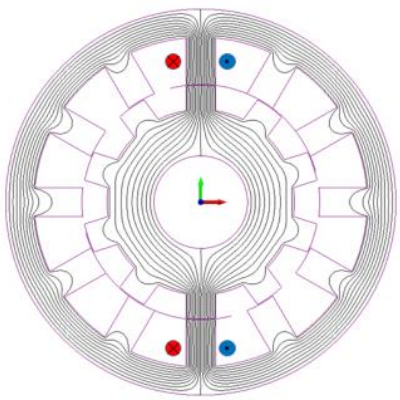

(a)

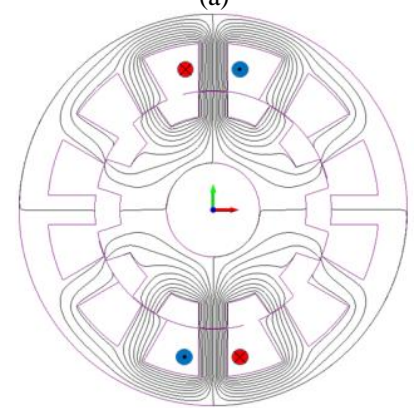

(b)

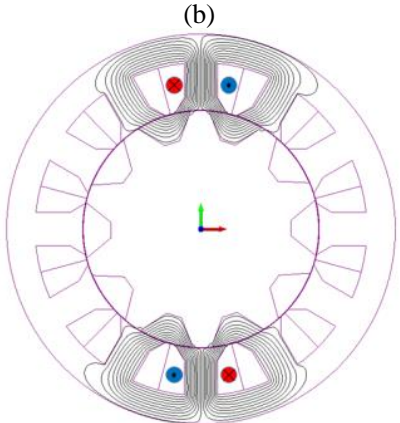

(c)

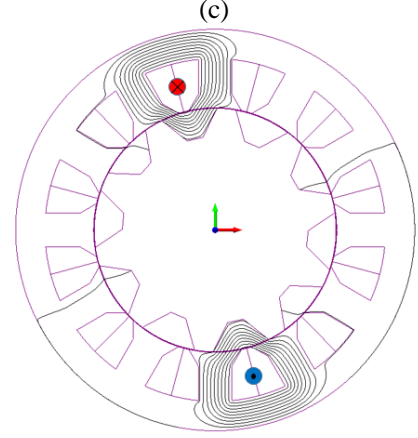

(d)

Fig. 3. Single-phase flux distribution at align posotion: (a) N-S connection of toothed rotor SRM. (b) N-N connection of toothed rotor SRM. (c) STW segmental rotor SRM. (d) FPW segmental rotor SRM.
In the STW segmental SRM, the MMF of the active phase is dropped exclusively across its associated stator teeth, two adjacent segmental rotor teeth, air-gap and the adjacent stator teeth. Since the segmental rotor SRM has fewer turns per coil, $12 \%$ less MMF can be generated with the same excitation current (15A) and the torque is $11.3 \%$ lower than in the conventional SRM, as shown in Fig. 4.The FP segmental SRM has the highest single-phase torque output, which is $58.2 \%$ higher than conventional SRM and $78.5 \%$ higher than STW segmental rotor SRM.

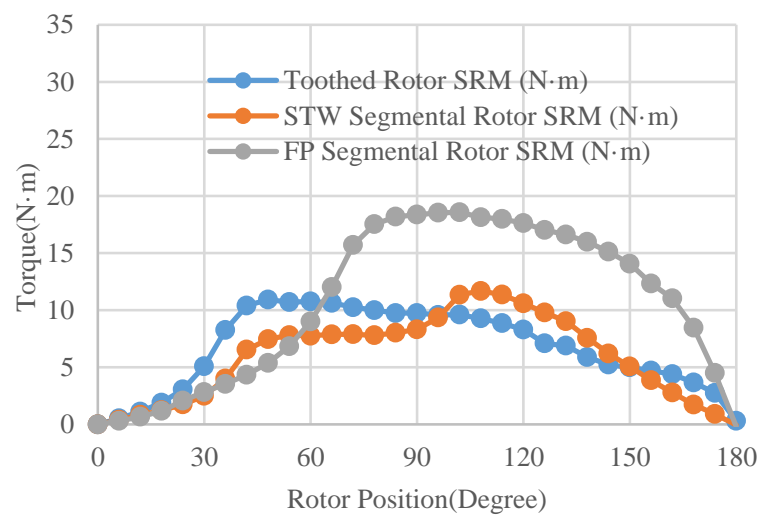

Fig. 4. 2D FEA torque output comparison under single-phase excitation.

\section{B. Multi-phase excitation}

Multi-phase excitation 2D FEA is then carried out. The segmental rotor SRM is first simulated with the same current as the toothed rotor SRM had in [11]. The phase current is 15A and the conduction width is $180^{\circ}$. Instantaneous torque waveforms are shown in Fig. 5. Torque comparisons are shown in Table III.

The segmental rotor SRM can produce $22.5 \mathrm{~N} \cdot \mathrm{m}$ average torque, which is $2.2 \%$ lower than the toothed rotor N-N connected SRM as the total MMF of segmental rotor SRM is $12.0 \%$ less than in the toothed rotor SRM. A FP winding connection is also simulated here as an alternative connection option for the segmental rotor SRM. It can produce $33.4 \mathrm{~N} \cdot \mathrm{m}$, which is $48.4 \%$ higher than the single tooth winding connection.

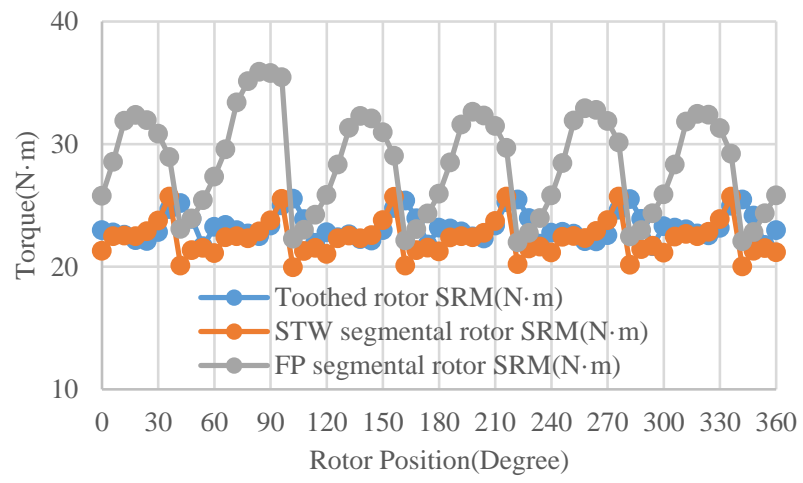

Fig. 5. 2D FEA torque output comparison under mullti-phase excitation.

TABLE III

TORQUE PERFORMANCE COMPARISON BETWEEN CONVENTIONAL AND SEGMENTAL SRMS

\begin{tabular}{|c|c|c|}
\hline & Average torque $(\mathrm{N} \cdot \mathrm{m})$ & Torque Ripple $(\%)$ \\
\hline Toothed rotor SRM & 23.2 & 16.7 \\
\hline STW Segmental rotor SRM & 22.5 & 25.8 \\
\hline FP Segmental rotor SRM & 28.4 & 48.9 \\
\hline
\end{tabular}


2D FEA flux distribution are compared to further explain the torque production difference between two winding arrangements. The flux distributions are shown in Fig. 6. There are always three phases conducting at the same time in the six-phase machine which are the out-going, intermediate and in-coming phases. As shown in Fig. 6(a), there are six short flux paths around six slots in the machine when it has a FP connection. All three phases generate positive torque during conduction. However, the STW type doesn't fully utilize the MMF. As shown in Fig. 6(b), half the MMF of the in-coming phase $\mathrm{C}$ hasn't been utilized. Half the MMF of the out-going phase A generates flux linkage for phase $\mathrm{F}$ which has already passed the aligned position. In this case, less positive torque and more negative torque is generated from every phase.

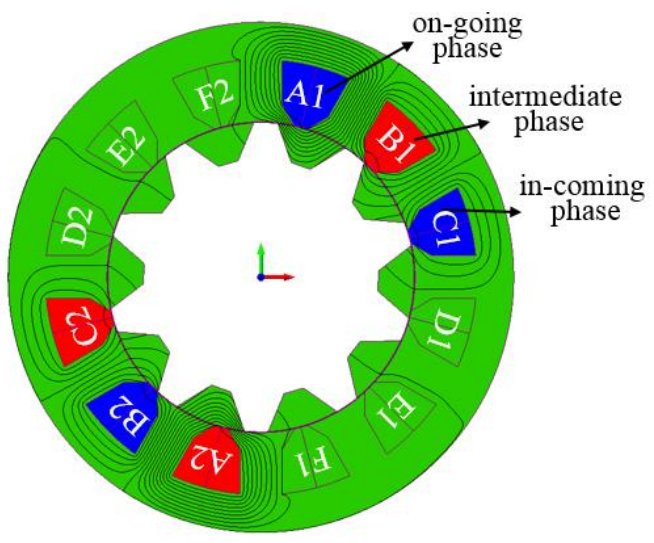

(a)

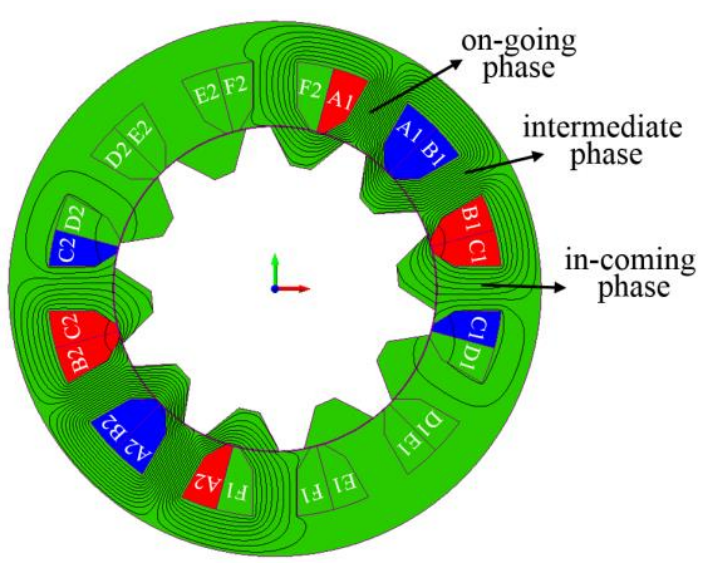

(b)

Fig. 6. 2D FEA flux distribution of the six-phase segental rotor SRM under multi-phase excitation: (a) FP (b) STW.

The comparison results above indicate that in terms of torque density the FP connection is much better than the STW connection for this six-phase segmental rotor SRM. However, the FP connection suffers from extremely long end windings. The biggest operational difference between the FP and STW machines is that the conduction length of MMF in each stator slot. In the STW machine, each slot has two phase windings thus the total conduction width of a slot MMF is $240^{\circ}$, whilst in the FP machine it is as same as the phase conduction width of $180^{\circ}$. This leads to periods of negative torque produced by any one slot MMF in the STW machine.

Based on the analysis above, the phase conduction width is subsequently limited to $120^{\circ}$ in the STW connection.
Keeping the RMS current the same, $120^{\circ} 18.4 \mathrm{~A}$ peak phase current can now be applied in the STW segmental rotor SRM. The torque comparison result is shown in Fig. 7. The $120^{\circ}$ conduction produce $11.5 \%$ higher average torque than with $180^{\circ}$ conduction, which validates the prediction. The torque ripple of the $120^{\circ}$ conduction case also has lower torque ripple.

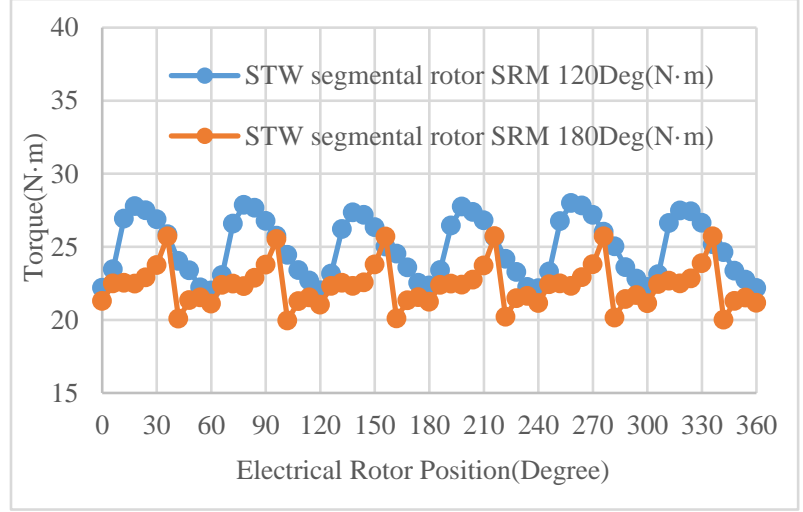

Fig. 7. 2D FEA torque output comparison under different conduction widths with the same RMS current.

TABLE IV

TORQUE PERFORMANCE COMPARISON STW SEGMENTAL SRMS WITH DIFFERENT CONDUCTION WIDTH

\begin{tabular}{|l|c|c|}
\hline & Average torque $(\mathrm{N} \cdot \mathrm{m})$ & Torque Ripple $(\%)$ \\
\hline $120^{\circ}$ conduction width & 24.9 & 24.0 \\
\hline $180^{\circ}$ conduction width & 22.4 & 25.8 \\
\hline
\end{tabular}

Different shapes of phase current have been applied to the STW segmental rotor SRM to optimize the torque performance. The single-phase current is shown in Fig. 8(a) and the single-slot MMF is shown in Fig. 8 (b).

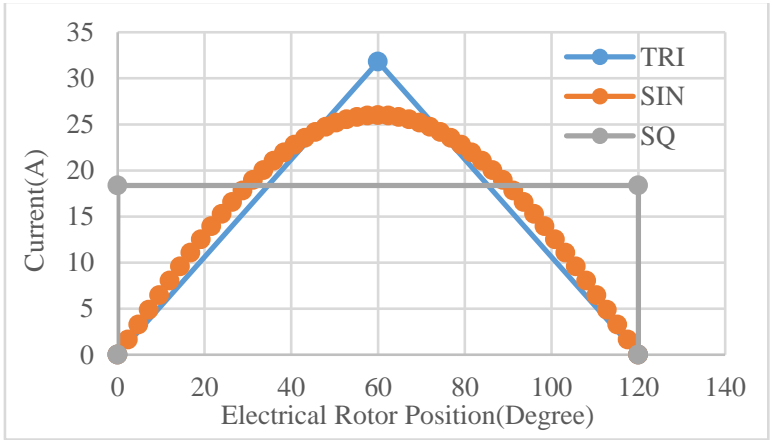

(a)

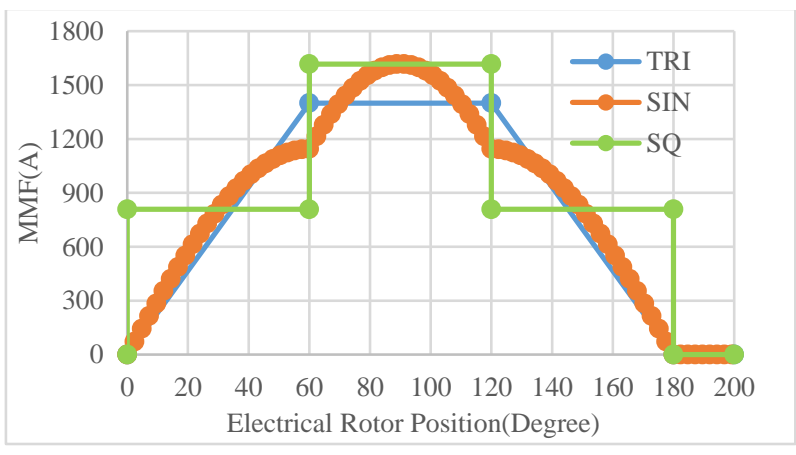

(b)

Fig. 8. Current waveforms in STW connection: (a) single-phase current (b) single-slot MMF 
The torque waveforms and comparisons are shown in Fig. 9 and Table V. The three torque waveforms are very similar. The sinusoidal current produces $1.5 \%$ higher average torque than the square waveform and $1.1 \%$ higher average torque than the triangular waveforms. The square shaped current produces the lowest torque ripple.

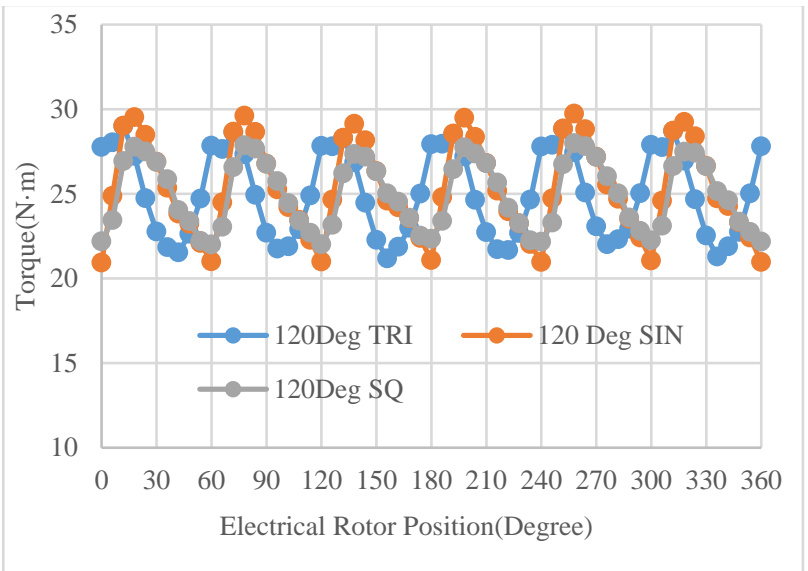

Fig. 9. 2D FEA torque output comparison under different current excitation in STW connetion.

TABLE V

TORQUE COMPARISONS OF STW CONNECTED SEGMENTAL ROTOR SRMS UNDER DIFFERENT CURRENT EXCITATION

\begin{tabular}{|c|c|c|}
\hline & Average torque $(\mathrm{N} \cdot \mathrm{m})$ & Torque Ripple $(\%)$ \\
\hline $\begin{array}{c}120^{\circ} \text { conduction } \\
\text { width TRI }\end{array}$ & 25.1 & 31.2 \\
\hline $\begin{array}{c}120^{\circ} \text { conduction } \\
\text { width SIN }\end{array}$ & 25.3 & 34.7 \\
\hline $\begin{array}{c}120^{\circ} \text { conduction } \\
\text { width SQ }\end{array}$ & 25.0 & 24.0 \\
\hline
\end{tabular}

Table VI and Table VII compare the performance of two SRMs at different operating speeds. At $200 \mathrm{r} / \mathrm{min}$, when the segmental rotor SRM is excited by a $120^{\circ} 18.4 \mathrm{~A}$ peak square waveform of current, it produces $9.1 \%$ higher average torque than the conventional SRM. With the same RMS current, the segmental rotor SRM has lower copper loss and core loss, thus higher efficiency can be achieved.

TABLE VI

PERFORMANCE COMPARISON BETWEEN CONVENTIONAL AND STW CONNECTED SEGMENTAL SRMS AT 200 R/MIN UNDER CURRENT CONTROL

\begin{tabular}{|c|c|c|}
\hline & Toothed rotor SRM & Segmental rotor SRM \\
\hline Active mass (kg) & 18.23 & 15.05 \\
\hline Torque (N.m) & 23.2 & 25.3 \\
\hline P_COPPER (W) & 236 & 209 \\
\hline P_CORE (W) & 24.4 & 5.8 \\
\hline Efficiency (\%) & 46.4 & 59.5 \\
\hline Power to mass ratio (W/kg) & 133.3 & 176 \\
\hline
\end{tabular}

At $4000 \mathrm{r} / \mathrm{min}$, SRMs are under voltage control and the core loss dominates the efficiency. The Type1 winding configuration which has been discussed in [11] is compared with the segmental rotor SRM here. These two machines both have only short flux paths. When pproducing the same torque, the segmental machine has much less rotor core loss which result from very short rotor flux paths (Fig. 10(b)).

TABLE VII

PERFORMANCE COMPARISON BETWEEN CONVENTIONAL AND STW CONNECTED SEGMENTAL SRMS AT 4000 R/MIN UNDER VOLTAGE CONTROL

\begin{tabular}{|c|c|c|}
\hline & Toothed rotor SRM & Segmental rotor SRM \\
\hline Torque $(\mathrm{N} \cdot \mathrm{m})$ & 9.7 & 9.8 \\
\hline P_COPPER (W) & 78 & 66 \\
\hline P_STATOR_CORE (W) & 115 & 119 \\
\hline P_ROTOR_CORE(W) & 68 & 25 \\
\hline Efficiency $(\%)$ & 94.0 & 95.1 \\
\hline Power to mass ratio (W/kg) & 222.8 & 272.7 \\
\hline
\end{tabular}

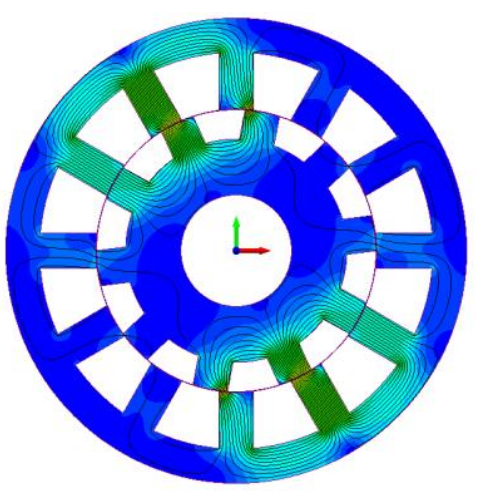

(a)

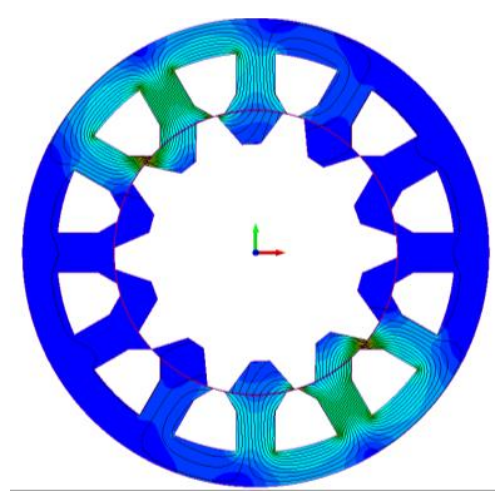

(b)

Fig. 10. Flux distrubution: (a) conventional toothed rotor SRM (b) segmental rotor SRM.

\section{CONCLUSION}

This paper investigates and compares the performance of a six-phase segmental rotor SRM with a six-phase conventional toothed rotor SRM. Both fully pitched and single tooth winding configurations are discussed. A fully pitched winding configured segmental rotor SRM produces much greater average torque than the conventional SRM, but suffers from very long end windings. The single tooth winding configured segmental rotor SRM can produce 9.1\% higher average torque with optimized magnetization current. Since segmental rotor SRMs have no rotor core back on the rotor 
and short flux paths all the time, they have reduced core loss and get higher efficiency throughout the speed range.

\section{REFERENCES}

[1] K. Kiyota and A. Chiba, "Design of Switched Reluctance Motor Competitive to 60-kW IPMSM in Third-Generation Hybrid Electric Vehicle," IEEE Transactions on Industry Applications, vol. 48, pp. 2303-2309, 2012.

[2] J. D. Widmer, R. Martin, and B. C. Mecrow, "Optimization of an 80kW Segmental Rotor Switched Reluctance Machine for Automotive Traction," IEEE Transactions on Industry Applications, vol. 51, pp. 2990-2999, 2015.

[3] B. C. Mecrow, E. A. El-Kharashi, J. W. Finch, and A. G. Jack, "Preliminary performance evaluation of switched reluctance motors with segmental rotors," Energy Conversion, IEEE Transactions on, vol. 19, pp. 679-686, 2004

[4] B. C. Mecrow, E. A. El-Kharashi, J. W. Finch, and A. G. Jack, "Segmental rotor switched reluctance motors with single-tooth windings," IEE Proceedings on Electric Power Applications, vol. 150 , pp. 591-599, 2003

[5] Z. Xu, J. Liu, M. Kim, D. H. Lee, and J. Ahn, "Characteristics Analysis and Comparison of Conventional and Segmental Rotor Type 12/8 Switched Reluctance Motors," IEEE Transactions on Industry Applications, pp. 1-10, 2018.

[6] B. Wang, L. Dong-Hee, and A. Jin-Woo, "A novel axial field SRM with segmental rotor: Concept, design and analysis," in 2013 Workshop on Power Electronics and Power Quality Applications (PEPQA), 2013, pp. 1-6.

[7] Z. Xu, K. Jeong, D. Lee, and J. Ahn, "Preliminary performance evaluation of a novel 12/8 segmental rotor type SRM," in 2016 19th International Conference on Electrical Machines and Systems (ICEMS), 2016, pp. 1-5.

[8] P. T. Hieu, D. Lee, and J. Ahn, "Design and control of a high speed segmental stator 4/3 switched reluctane motor," in 2016 IEEE Transportation Electrification Conference and Expo, Asia-Pacific (ITEC Asia-Pacific), 2016, pp. 767-772.

[9] X. Chen and J. Wu, "Calculation of inductances with 3-D FEM for SRM with segmental rotors and fully-picthed windings," in 17th International Conference on Electrical Machines and Systems (ICEMS), 2014, pp. 1822-1824.

[10] X. Chen, J. Wang, V. I. Patel, and P. Lazari, "A Nine-Phase 18-Slot 14-Pole Interior Permanent Magnet Machine with Low Space Harmonics for Electric Vehicle Applications," IEEE Transactions on Energy Conversion, vol. 12, pp. 1-10, 2016.

[11] X. Deng, B. Mecrow, R. Martin, and S. Gadoue, "Effects of Winding Connection on Performance of a Six-Phase Switched Reluctance Machine," IEEE Transactions on Energy Conversion, vol. 33, pp. 166-178, 2018.

[12] X. Deng, B. Mecrow, H. Wu, and R. Martin, "Design and Development of Low Torque Ripple Variable-Speed Drive System With Six-Phase Switched Reluctance Motors," IEEE Transactions on Energy Conversion, vol. 33, pp. 420-429, 2018

[13] X. Deng, B. Mecrow, H. Wu, R. Martin, and Y. Gai, "Cost-Effective and High-Efficiency Variable-Speed Switched Reluctance Drives With Ring-Connected Winding Configuration," IEEE Transactions on Energy Conversion, vol. 34, pp. 120-129, 2019. 